\title{
Shattered rim and shelling of high-speed railway wheels in the very-high-cycle fatigue regime under rolling contact loading
}

\author{
Tao Cong ${ }^{\mathrm{a}, \mathrm{b}}$, Jianmin Han ${ }^{\mathrm{a}}$, Youshi Hong ${ }^{\mathrm{c}}$, Joseph P. Domblesky ${ }^{\mathrm{d}}$, Xiaolong Liu ${ }^{\mathrm{a}, *}$ \\ ${ }^{a}$ School of Mechanical Electronic \& Control Engineering, Beijing Jiaotong University, Beijing 100044, China \\ ${ }^{\mathrm{b}}$ Metals \& Chemistry Research Institute, China Academy of Railway Sciences Corporation Limited, Beijing 100081, China \\ ${ }^{\mathrm{c}}$ State Key Laboratory of Nonlinear Mechanics, Institute of Mechanics, Chinese Academy of Sciences, Beijing 100190, PR China \\ ${ }^{\mathrm{d}}$ Mechanical Engineering Department, Marquette University, Milwaukee, WI 53233, USA
}

\section{A R T I C L E I N F O}

\section{Keywords:}

High-speed railway wheel

Shattered rim

Shelling

Very-high-cycle fatigue

Rolling contact loading

Crack initiation

\begin{abstract}
A B S T R A C T
Due to the improvement of the wear property, rolling contact fatigue including shattered rim and shelling are the main failure causes of the high-speed railway wheels. In this paper, shattered rim and shelling occurred on the service wheels of the China Railway High-speed (CRH) trains were systematically investigated. The recorded data of the last ten years CRH operation indicated that all shattered rims and shelling were detected with serving $>10^{6} \mathrm{~km}$ (corresponding to the fatigue life $10^{7}-10^{9}$ cycles) which is very-high-cycle fatigue (VHCF). The crack initiation region of shattered rim located at the depth of $10-25 \mathrm{~mm}$ from the tread, while that of shelling located at the depth $<10 \mathrm{~mm}$ from the tread. The VHCF features under rolling contact loading were observed on the opening crack surfaces, i.e., similar VHCF features in uniaxial loading including the defect, fish-eye, and crack propagation region and unique VHCF features of the three dimensional crack surface feature, beach bands uniformly distributed in the crack propagation region, absence of fine granular area (FGA). The VHCF model considering the stress distribution, defect size and hardness were applied to discuss the failure mechanism of the shattered rim and shelling.
\end{abstract}

\section{Introduction}

Increased running speeds and axle loads are the main development direction in modern railway systems and continue to pose new challenge with respect to performance of key systems such as the wheel/rail pair [1,2]. Rolling contact fatigue (RCF) represents one of the main failure causes on wheel/rail pair and is attributed to the repeated contact between wheel and rail [3-5]. Three typical RCFs have been defined [6-8], i.e., surface initiated crack, subsurface crack initiation and interior initiated crack. In general, the surface and subsurface initiated crack tend to cause shelling on the tread $[9,10]$, and the shattered rim is the results of interior crack initiation $[11,12]$. Due to the improvement of wear property, the failure caused by wear is rare while rolling contact fatigue especially the subsurface and interior crack initiation become more common which are lacking in systematic investigation.

The surface initiated crack typically developed as a consequence of frictional rolling/sliding contact that causes localized plastic flow of the surface material. As the cyclic strain localization occurred in the form of persistent slip bands, a surface crack is formed. Such cracks typically propagate at a shallow angle to the surface, deviating first into an almost radial and later into a circumferential direction of growth due to the shear stress [13]. This is well known for a number of pure metals and alloys. However, the combined effects of material defects and the contact shear stress profile with a maximum shear stress below surface are responsible for the

\footnotetext{
* Corresponding author.

E-mail address: liuxiaolong@bjtu.edu.cn (X. Liu).
} 
subsurface initiated crack and the interior crack initiation [14,15]. Unlike the low-cycle fatigue regime of surface crack initiation, the formation mechanisms of subsurface and interior crack initiation in the failure of railway wheels are discussed rarely.

In recent years, the topic of very-high-cycle fatigue (VHCF) has drawn significant interest from industry because many components in structural application such as wheels, turbine engines and bearings can accumulate $10^{7}$ to $10^{10}$ cycles in service [16-18]. In some cases, high-strength steels failed at the stress lower than the conventional fatigue limit and the crack initiated from interior nonmetallic inclusions. The whole region of crack initiation and early propagation exhibits a "fish-eye" pattern and a relatively rough granular morphology is often observed surrounding the inclusion, which is called fine granular area (FGA) [19,20]. Grabulov et al. $[21,22]$ reported that butterfly cracks and nano-crystalline ferrite formed around non-metallic inclusions in the VHCF under rolling contact loading. Due to the fact that the serviced railway wheels bear the fatigue life beyond $10^{7}$ under rolling contact loading, this raises an interesting question: Do the subsurface and interior crack initiation of the railway wheels belong to VCHF? If yes, what the characterizations of the VHCF under rolling contact loading are?

The shattered rim and shelling in railway wheels of China Railway High-speed (CRH) trains were systematically investigated in this paper. First, the severing mileage and crack initiation location for the shattered rim and shelling occurred in CRH for the last ten years were collected and recorded. The fatigue life and crack initiation location for the shattered rim and shelling of railway wheels were presented by statistical indicating that the shattered rim and shelling belong to the VHCF under rolling contact loading. Then, the crack surfaces taken from the failed railway wheels were opened to observe the characterizations of VHCF under rolling contact loading. Finally, the VHCF model considering the stress distribution, defect size and hardness were applied to discuss the failure mechanism of the shattered rim and shelling.

\section{Material and experimental procedures}

\subsection{Testing wheels and experimental procedures}

Four railway wheels (two with shattered rims and two with shelling) were removed from the CRH for further investigation. It is worth noting that shelling in this paper refer to the subsurface defect induced failure. Fig. 1 shows two removed shattered rims on $\mathrm{CRH}$ rail vehicles. A crack was observed on the rim which has extended to the tread as shown in Fig. 1a, called penetrating shattered rim. No crack was observed on the tread and rim of the wheel as shown in Fig. 1b. However, a crack was detected by ultrasonic detection, which called non-penetrating shattered rim. The non-penetrating shattered rim will extend to the rim with further service. Fig. 2 presents two typical shelling on the CRH wheels that caused the failure of wheels. The ultrasonic detection was applied to detect the crack under the tread. A crack with the area of $30 \mathrm{~mm} \times 30 \mathrm{~mm}$ was detected in the wheel (Fig. 2a), and the location is $3 \mathrm{~mm}$ depth from the tread. The wheel in Fig. $2 \mathrm{~b}$ also contained a crack with the area of $8 \mathrm{~mm} \times 20 \mathrm{~mm}$, and the location is about $4 \mathrm{~mm}$ depth from the tread surface.

In order to observe the crack surface, the crack was opened by mounting one side of the wheel on a fixture and cut the other side with an electric cutting saw. Then, optical microscopy (OP), scanning electron microscopy (SEM) with energy dispersive spectrum analysis (EDS), and 3 Dimensional Confocal Microscope Phase Shift MicroXAM were applied to systematically observe the crack surface. Radial sections containing cracks were then prepared for metallographic analysis. Metallographic preparation consisted of mounting the specimens and sequentially grinding the surfaces using 400-2000 grit emery papers and polishing. Etching was performed using a $4 \%$ Nital solution. Brinell hardness measurements were performed on the wheel profile in the radial direction.

\subsection{Material}

The material in the railway wheels consisted of a forged medium carbon steel ER8 having the nominal chemical composition given in Table 1. The heat-treatment of the wheels is that heat up to Austenite transition temperature and water quench on the tread. For getting excellent hardness of wheel tread that bears the contact loading, quenching with spraying water was conducted during
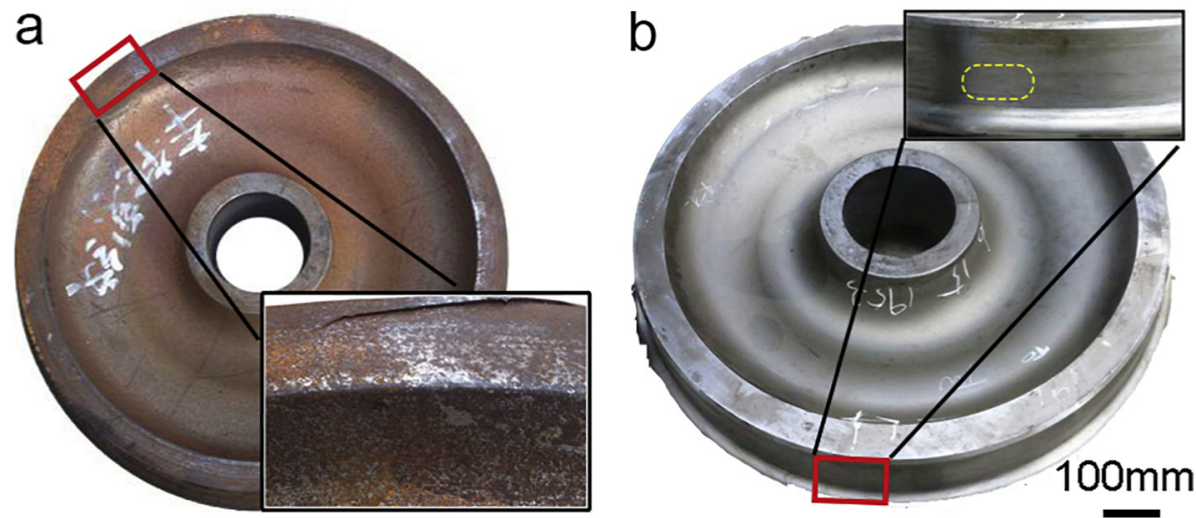

Fig. 1. Photographs taken from CRH wheels showing (a) penetrating, and (b) non-penetrating shattered rims. 
a

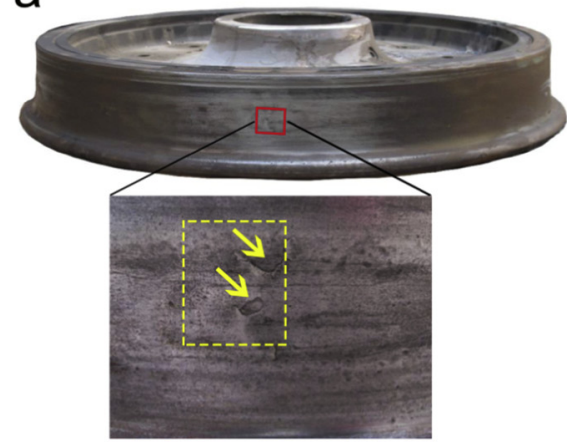

b

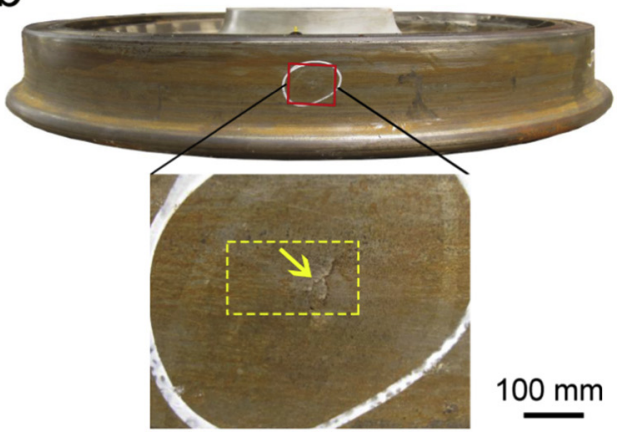

Fig. 2. Photographs taken from $\mathrm{CRH}$ wheels showing (a) multipoints, and (b) single point shelling.

Table 1

Nominal chemical composition (wt\%) of railway wheel steel used in the investigation.

\begin{tabular}{llllllll}
\hline $\mathrm{Fe}$ & $\mathrm{C}$ & $\mathrm{Si}$ & $\mathrm{Mn}$ & $\mathrm{P}$ & $\mathrm{S}$ & $\mathrm{Cr}$ \\
$\mathrm{Bal}$ & 0.56 & 0.40 & 0.80 & 0.020 & 0.015 & 0.30 & 0.30 \\
\hline
\end{tabular}

heat-treatment. Due to cooling rates at tread and interior of wheel rim, difference in ferrite fraction was observed as shown in Fig. 3. The microstructure under the tread is abundant pearlite with trace ferrite (Fig. 3a). The microstructure in the interior was found to consist of pearlite and ferrite (Fig. 3b), and the distribution of the ferrite is heterogeneous. Fig. 4 presents the typical inclusions in the wheel steels. The size of the inclusion is about $20 \mu \mathrm{m}$. Nonmetallic inclusion is prevalent in the steels. The aluminium acted as deoxidizer during the smelting processing of steels which results in the introduction of aluminium oxide inclusions to steels. In addition, the mechanical properties of the material were measured by tensile testing on an MTS 810 system with cylindrical specimens of $6 \mathrm{~mm}$ in diameter and at a strain rate of $10^{-4} \mathrm{~s}^{-1}$. Five specimens were tested to obtain the yield strength of $673 \mathrm{MPa}$, the tensile strength of $950 \mathrm{MPa}$ and the uniform elongation of $11.5 \%$ for the material.

\subsection{Finite element modeling of wheel/rail contact}

First, use the Solidworks to build the geometry model of the wheel and a piece of rail as shown in Fig. 5. The diameter of the wheel is $860 \mathrm{~mm}$. About 0.2 million of 3D elements are used in the model (An 8-node linear brick, reduce integration in ABAQUS). The average element length that away from the contact surface of the wheel/rail is $5 \mathrm{~mm}$. Due to the non-linearity of contact analysis, contact surface need fine mesh for accurate stress analysis. The average element length near the contact surface is $1 \mathrm{~mm}$. Due to symmetry and to improve the efficiency of the calculation, only $1 / 6$ of the wheel was modelled. A pilot point is connected to the wheel using rigid link elements. All the external loading and boundary conditions of the wheel are applied on the pilot point. Due to the variant service axle load, maximum design axle load of $150 \mathrm{kN}$ was applied in the stress analysis. Obviously the calculated stress is larger than the serviced stress. The variation trend and distribution of the contact stress on the wheel are similar which has reference significance in the failure analysis. The wheel/rail contact surfaces are regarded as surface-to-surface contact elements. The augmented Lagrangian method is used for contact simulation. The friction model is the coulomb friction model. The coulomb friction model defines an equivalent shear stress, which is proportional to the contact pressure.
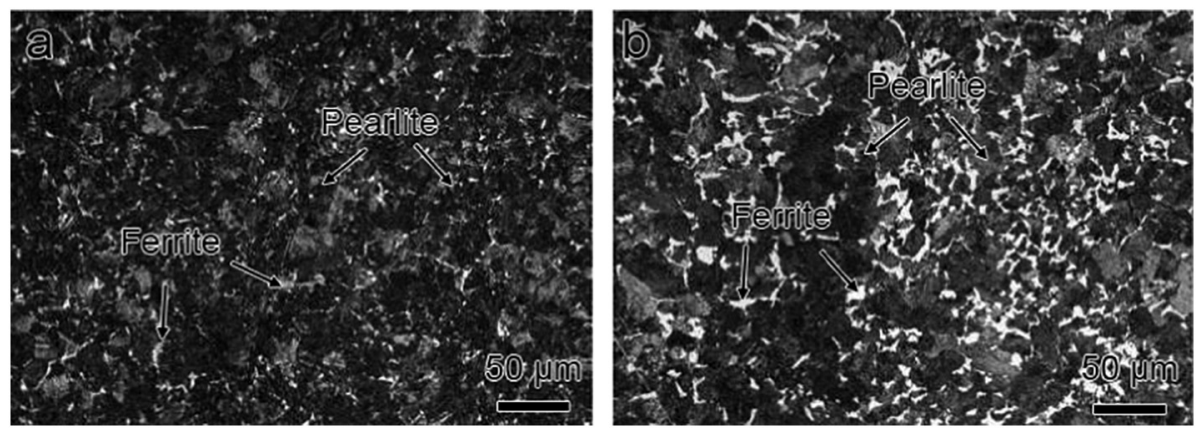

Fig. 3. Microstructure of the wheels by optical microscopy, (a) surface, and (b) interior. 

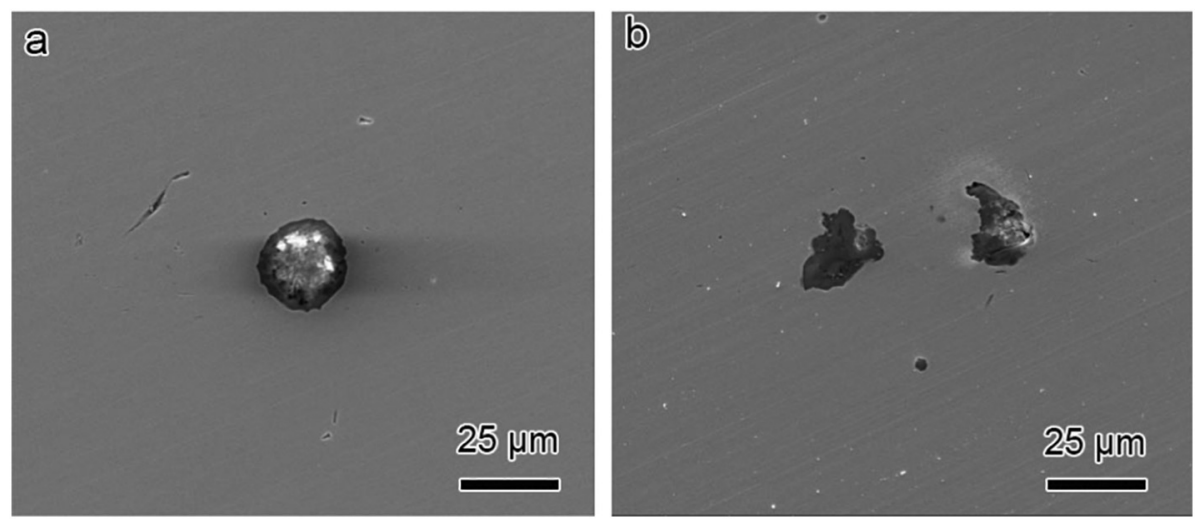

Fig. 4. Inclusions in the steels, (a) Type I, and (b) Type II.

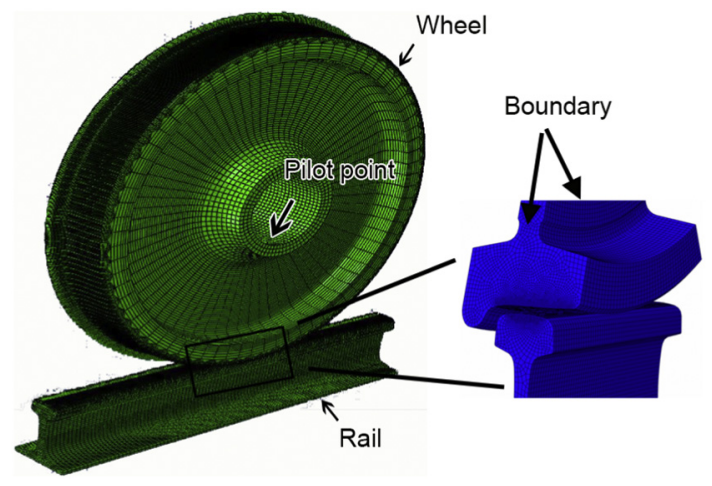

Fig. 5. 3D finite element model of wheel/rail contact.

\section{Results and discussion}

\subsection{Fatigue life and crack initiation location}

The severing mileage and crack initiation location for the shattered rim and shelling occurred in the CRH trains have been recorded. It is worth noted that few shattered rim and shelling were reported in the previous literatures [3-6]. The data of corresponding fatigue life and crack initiation location is not abundant which limits the systematic investigations. For more than ten years operation, abundant shattered rim and shelling on the CRH wheels were collected and recorded which make the systematic investigation possible. As the key components, railway wheels in the CRH are under close surveillance. All the wheels are detected on by the automatic online ultrasonic detection every two days. During the primary repair, secondary repair and third repair, the careful ultrasonic detection will be conducted for every wheel. Once the cracks in the wheels were detected, the severing mileage and crack initiation location were recorded. Fig. 6 presents the depth of the crack initiation region from the tread versus the fatigue life for

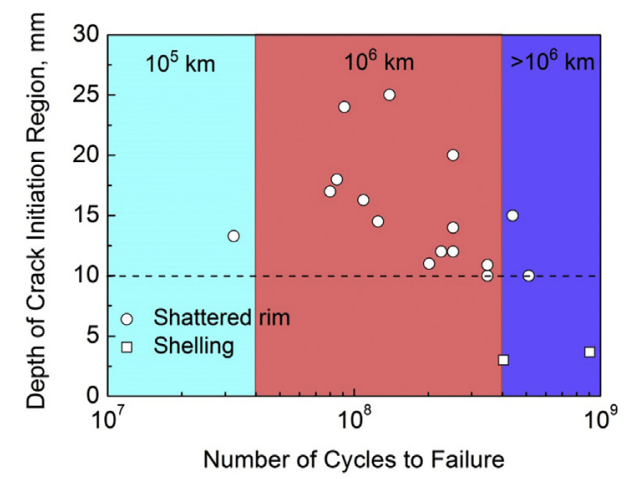

Fig. 6. Depth of crack initiation region versus fatigue life. 

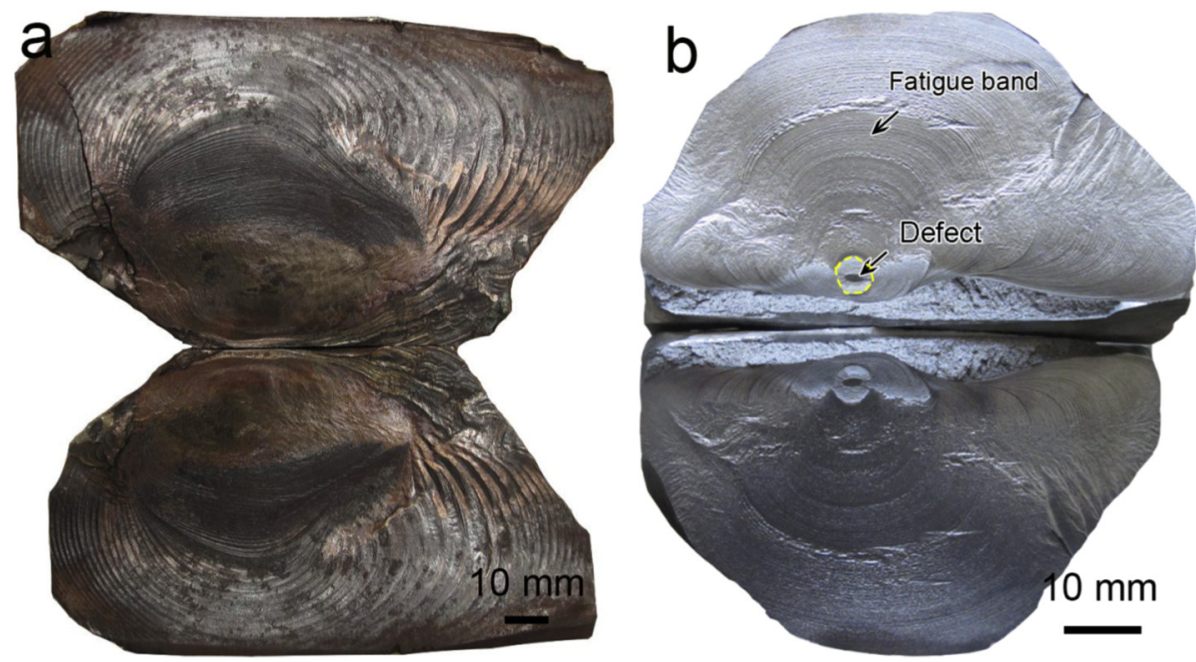

Fig. 7. Shattered rim surfaces, (a) penetrating, and (b) non-penetrating.

shattered rim and shelling. The fatigue life is independent with the depth of the crack initiation region. The depth of the crack initiation region from the tread is in the range of $10-25 \mathrm{~mm}$ for all the shattered rims, and that for shelling is $<10 \mathrm{~mm}$. The wheels with shattered rim or shelling were recorded with the service of $10^{5}-10^{7} \mathrm{~km}$, and the corresponding fatigue life is within a range of $10^{7}-10^{9}$ cycles. In general, the service stress is below the conventional fatigue limit. Considering the crack initiation site, service stress and fatigue life, the shattered rim and shelling can regarded as VHCF behavior.

\subsection{Characteristics of shattered rim}

Fig. 7 presents the opening crack surfaces of the shattered rims. Fig. $7 \mathrm{a}$ is the crack surfaces of the penetrating shattered rim corresponding to the wheel in Fig. 1a. Although the crack surfaces have been contaminated due to oxidation and the crack initiation region is slightly blurred due to the corrosion, it is clear that the crack initiated and fatigue fractured from interior of the wheel. Fig. $7 \mathrm{~b}$ is the non-penetrating shattered rim surfaces corresponding to the wheel in Fig. 1b. The crack surface is fresh and clear which is helpful for the investigation of crack initiation mechanism. The crack initiation region contains a defect surrounding with a flat region marked by dot line. Abundant beach bands were located in the crack growth region.

The fracture surface of shattered rims was observed by the scanning electron microscope (SEM) and 3 Dimensional Confocal Microscope Phase Shift MicroXAM. Fig. 8a presents the SEM results, indicating three typical region with different morphology, i.e., the defect (Def), Fish-eye (FiE), and crack propagation region with beach marks (Band). Fig. 8b and c presents the 3D shape of the fracture surface. The defect, the fish-eye and the crack propagation region are not on the same plane. It can be seen from Fig. $8 \mathrm{c}$ that the defect and fish-eye have a height difference of about $0.4 \mathrm{~mm}$. This is different from previously reported fracture surfaces of VHCF

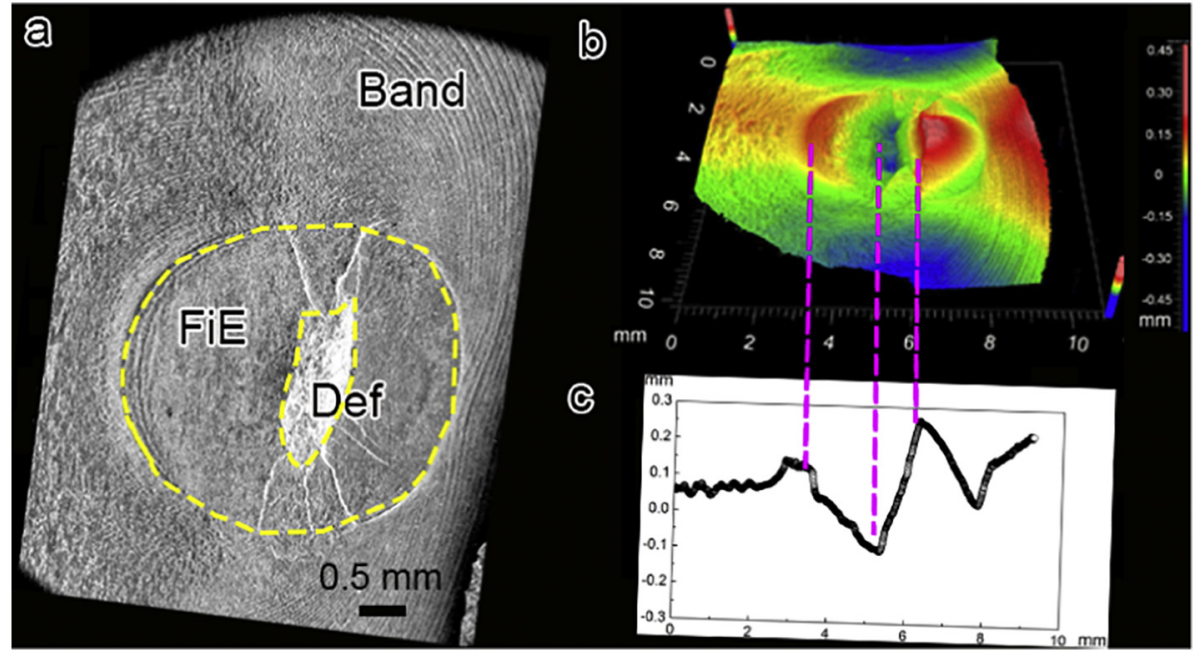

Fig. 8. Fracture surface morphology by SEM and phase shift microXAM-3D, (a) 2D, (b) 3D and (c) fluctuate in the profile. 

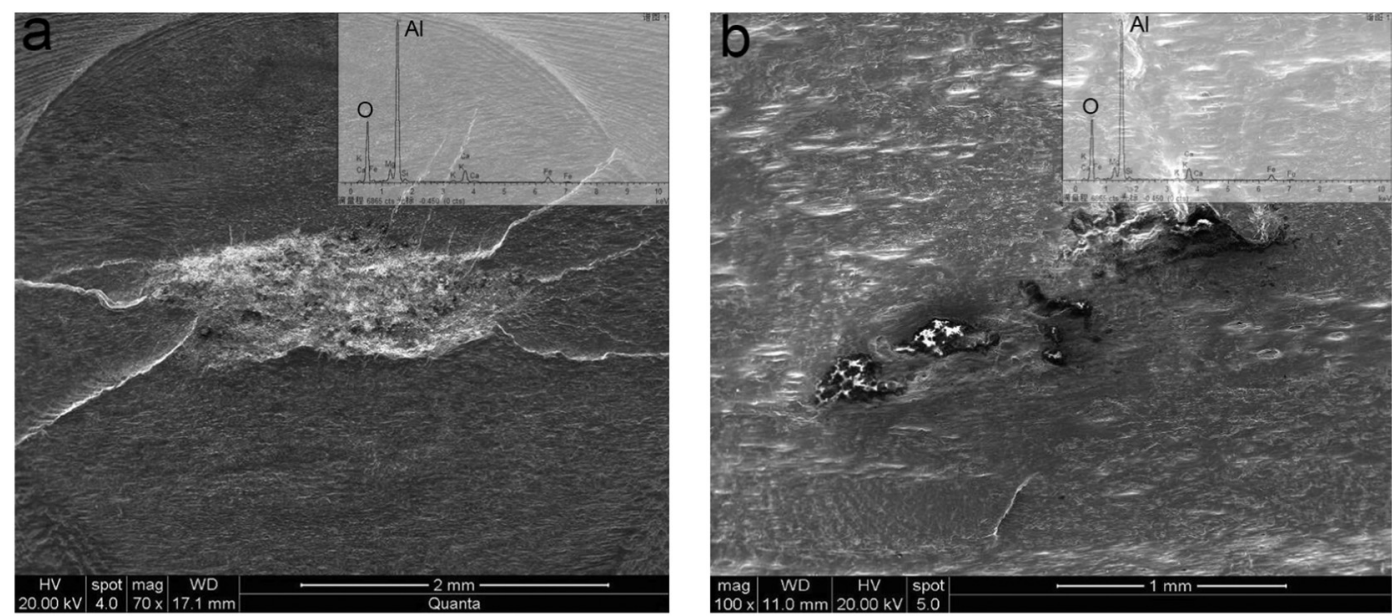

Fig. 9. Defects for the shattered rims, (a) one defect, and (b) defect cluster, Insets showing the EDS results of the defects.

in uniaxial loading [23], where the defect, fish-eye, and crack propagation region all lie on the same plane.

For shattered rims, rolling contact loading is applied on the wheels, which is multi-axial stress state. Due to the large confining pressures under the contact which normally suppresses any Mode I deformation of the crack, the crack propagates mainly in a mixed Mode II-Mode III [7]. In general, the Mode II-Mode III crack presents the three dimensional characteristics. The beach band in the crack propagation region is another unique feature of the VHCF under rolling contact loading. The essentially uniform equidistance distribution of beach bands indicated that the crack propagation rate is constant which is different from the rapid propagation for the case of uniaxial loading. Although FGA is the typical feature in the crack initiation region for VHCF under uniaxial loading [24], FGA was not observed around the defect for the case of rolling contact loading (Fig. 8a). Fig. 9 presents the defects for the shattered rims, including one defect type and defect cluster type. The results by energy dispersive spectrum analysis (EDS) indicate that the defects are aluminium oxide as shown in the insets of Fig. 9. Calcium oxide was also observed in other shattered rims. Defect type, size and location play an important role in the VHCF of steels $[25,26]$. Therefore, the VHCF under rolling contact loading demonstrates some typical features of VHCF under uniaxial loading, but also shows some distinct characteristics.

\subsection{Characteristics of shelling}

Fig. 10a presents the sample containing the shelling crack cut from the wheel shown in Fig. 2b. Surfaces A, B and C are prepared for crack and microstructure observations. The cutting position on the tread was marked by the arrow for opening the crack. The opening crack surfaces are presented in Fig. 10b. The crack surfaces were somewhat corroded and extruded, but the fatigue fracture features were evident. It is worth noting that part of the crack surface was missing due to wearing. The crack initiation site can be distinguished (Marked by the red box). The morphology is similar with that in Fig. 8, which can be regarded as the same fatigue behavior. Fig. 10c presents the crack initiation site observed by SEM. Defect was found in this region which were confirmed by EDS. Fig. 9d presents the crack propagation region. Beach bands were observed in this region.

Fig. 11a presents the three surfaces prepared for observations. Surface A contains a $19 \mathrm{~mm}$ length crack, and the deepest location of the crack is about $2.3 \mathrm{~mm}$. The crack in Surface B is $7.7 \mathrm{~mm}$ in length, and that in Surface C is also $7.7 \mathrm{~mm}$. The deepest locations are $2 \mathrm{~mm}$ and $2.3 \mathrm{~mm}$ respectively. Fig. 11b presents the morphology of the crack, indicating that the crack growth direction is almost parallel to the tread. Second cracks were observed for all the cases, which is related to the rolling contact loading. Fig. 11c and d present the microstructure around the cracks. A shear plastic deformation microstructure layer with $70 \mu \mathrm{m}$ thickness (marked by arrows) was observed around the crack, which supported that the crack is driven by shear stress.

Fig. 12a presents another sample containing the shelling crack cut from the wheel in Fig. 2a. The cutting position on the tread was marked by the arrows for opening the crack. A surface was prepared for crack and microstructure observations which were presented in Fig. 12. The opening crack surfaces are presented in Fig. 12b. It is indicated that fatigue fracture characteristics were presented although the crack surfaces were corroded and extruded. Shelling occurred on the crack surface of tread. Fig. 13a presents the metallographic surface prepared for observations. The service load of the wheels is rolling contact, which causes plastic deformation (marked by arrows) on the tread as shown in Fig. 13b. The grain refinement occurred in the tread, and the grain size increases gradually with an increasing depth. The microstructures around the cracks near tread are presented in Fig. 13c and d, indicating also evident grain refinement (marked by arrows).

\subsection{Multiaxial stress state analysis}

As mentioned above, the fracture surfaces for the case of interior and subsurface crack initiation are different, which is attributed to the stress distribution of rolling contact loading. Here, finite element method was applied to analyze the stress around the contact 

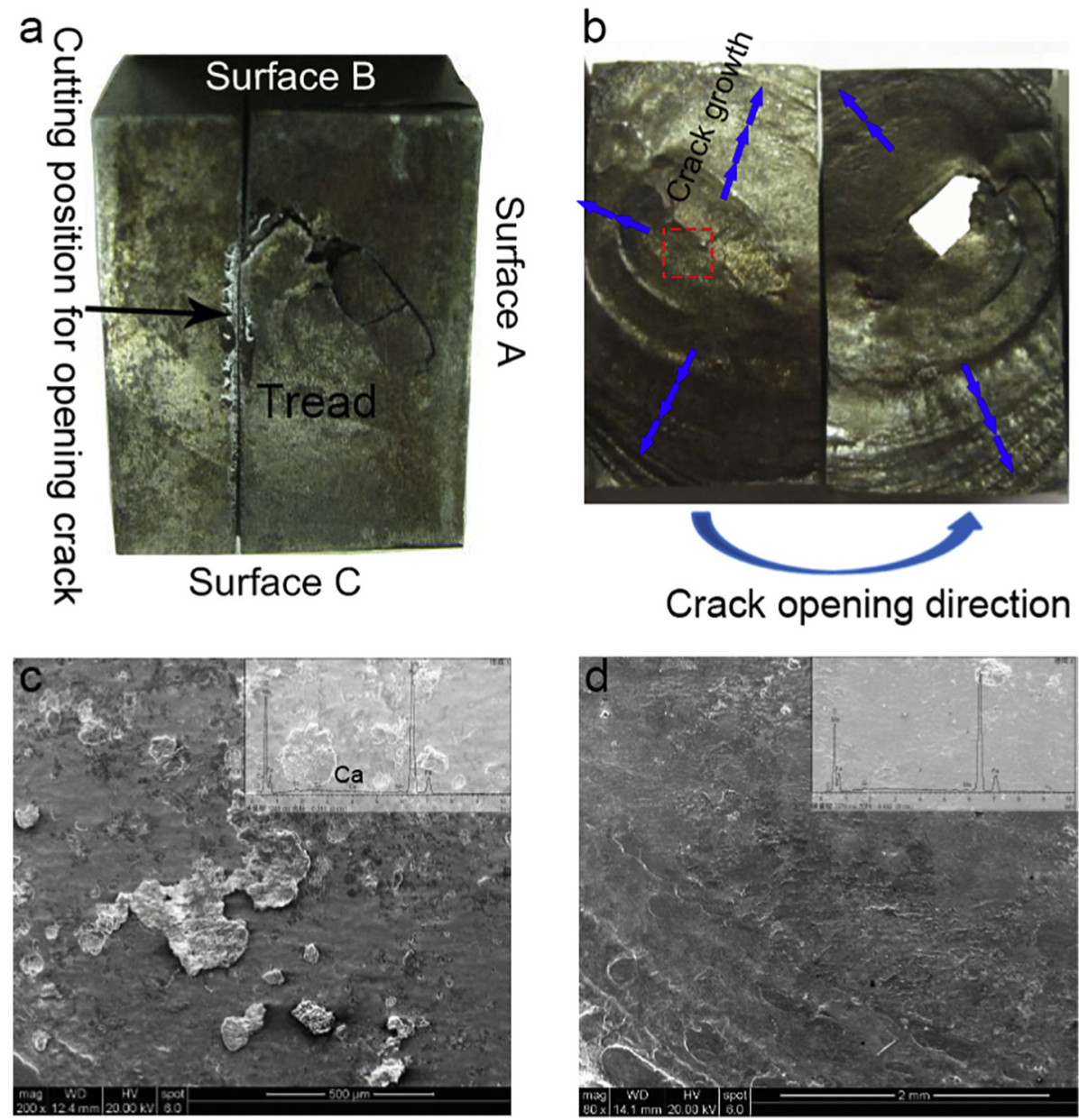

Fig. 10. Observations of the opening crack surface, (a) sample cut from the wheel, (b) opening crack surface, (c) crack initiation site by SEM, and (d) crack propagate region.

surface. The multiaxial stress consists of a pressure stress in the radial direction (Fig. 14a), a shear stress in axle direction (Fig. 14b) and a shear stress in circumference direction (Fig. 14c). The results in Fig. 14 indicated that only a small region of the contact location bears high stress, the maximum stress located at the depth of about $2 \mathrm{~mm}$ while the stress in the other parts of the wheel is almost zero. Fig. 14d presents the stress variation along the radial direction of the wheel. For the case of shelling (subsurface crack initiation) with the depth $0-10 \mathrm{~mm}$, the pressure stress is very high and decreases with the increase of the depth. The existence of the high pressure will cause the severe plastic deformation near the tread (Fig. 10c and 12c) and the press of the crack surfaces (Fig. 9b and 11b). The two shear stress increase first from the tread surface to the $2 \mathrm{~mm}$ depth of the wheel, and the maximum shear stress occurs at about $2 \mathrm{~mm}$ depth from the tread. These two shear stresses are the driven force of the subsurface crack initiation and propagation. For the case of shattered rim (interior crack initiation) with the depth $10-25 \mathrm{~mm}$, the pressure stress is in the elastic stage, and no evident press between the crack surface was observed (Fig. 6). Meanwhile, the two shear stresses are also in the low level. It is consistent with VHCF features of a relatively low cyclic stress below conventional fatigue limit and beyond $10^{7}$ fatigue cycles.

\subsection{Formation mechanism of shattered rim and shelling}

As mentioned above, the formation mechanisms of shattered rim and shelling were related to the defect induced subsurface and interior crack initiations, which is a long-standing topic for researchers involved in the investigation of VHCF. Clarifying fatigue mechanisms and controlling factors have been proposed. Although a number of factors can influence fatigue strength, such as the defect size, shape, chemical composition, etc. These factors have been substantially investigated. Murakami presented a simple and useful method based only two basic quantities for the prediction of fatigue limit $\sigma_{\mathrm{w}}[25,26]$ :

$$
\sigma_{\mathrm{w}}=\frac{1.56(\mathrm{Hv}+120)}{(\sqrt{\text { area }})^{1 / 6}}
$$

Where the Vickers hardness (Hv) is the representative material parameter, and $\sqrt{\text { area }}$ is defined as the square root of the area 
a

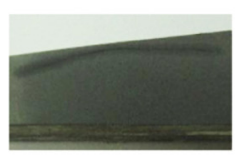

Surface A

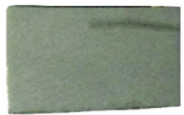

Surface B

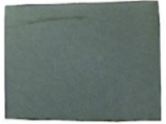

Surface C b

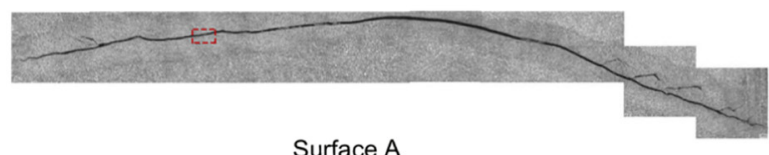

Surface A

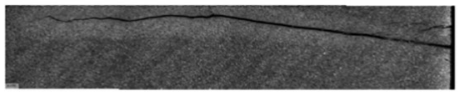

Surface B

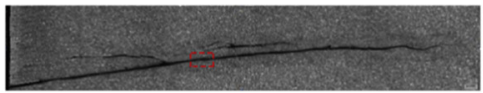

Surface C

\section{C}

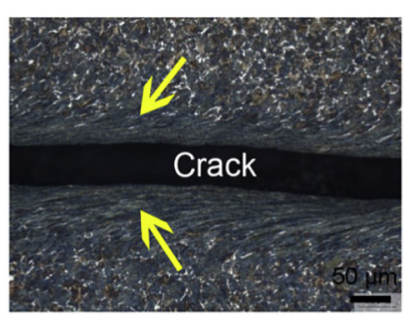

d

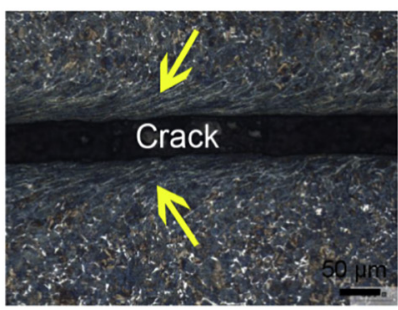

Fig. 11. Observations of the cracks and microstructure, (a) metallographic observation surface A, B and C, (b) Cracks in Surface A, B and C, (c) and (d) microstructure around the cracks.

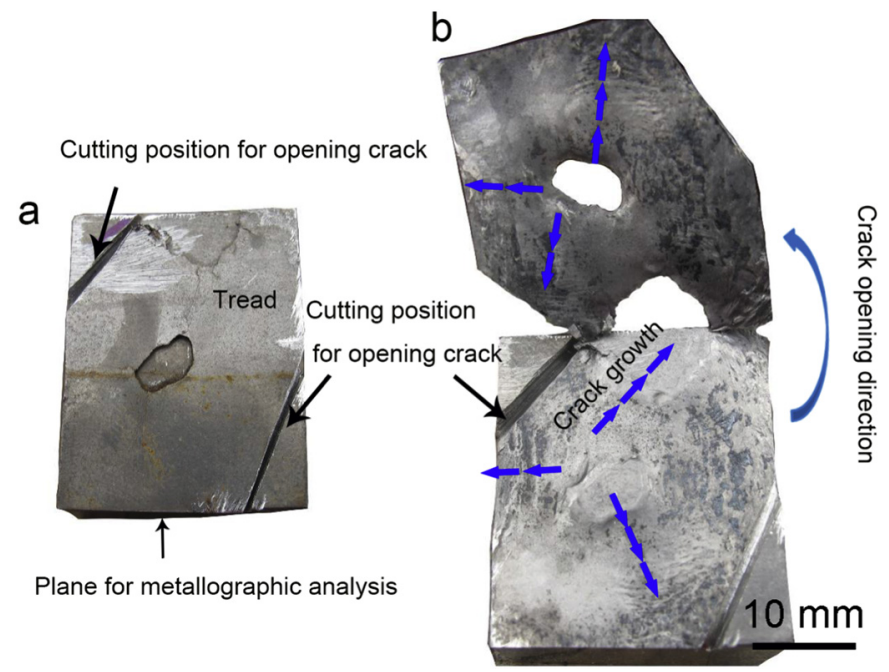

Fig. 12. Observations of the opening crack surface, (a) sample cut from the wheel, (b) opening crack surface.

obtained by projecting a small defect or crack onto a plane perpendicular to the maximum principal stress.

Although the Murakami model is applied to evaluate the VHCF in uniaxial loading, the fatigue strength under rolling contact loading can be regarded as proportional to the hardness and inversely proportional to the defect size. According to Eq. (1), the defect size and hardness distribution were measured. Fig. 15 presents the defect size that induced shattered rim and shelling of the wheels. In general, the size of defects that induced fatigue is larger than the average defect size in the material. In Fig. 15, The minimum size of defect that induced shattered rim and shelling is $56.7 \mu \mathrm{m}$, which is almost more than three times of the average defect size (20 $\mu \mathrm{m})$. The maximum defect size is $1439.4 \mu \mathrm{m}$, about 72 times of the average defect size. Therefore, all of the defect sizes that induce crack initiation exceeded the average size. As listed in Eq. (1), the fatigue strength decrease with the increase of the defect size.

The hardness for the wheel profile has been tested by the method of Brinell hardness. The wheel has served for a while. Fig. 16 

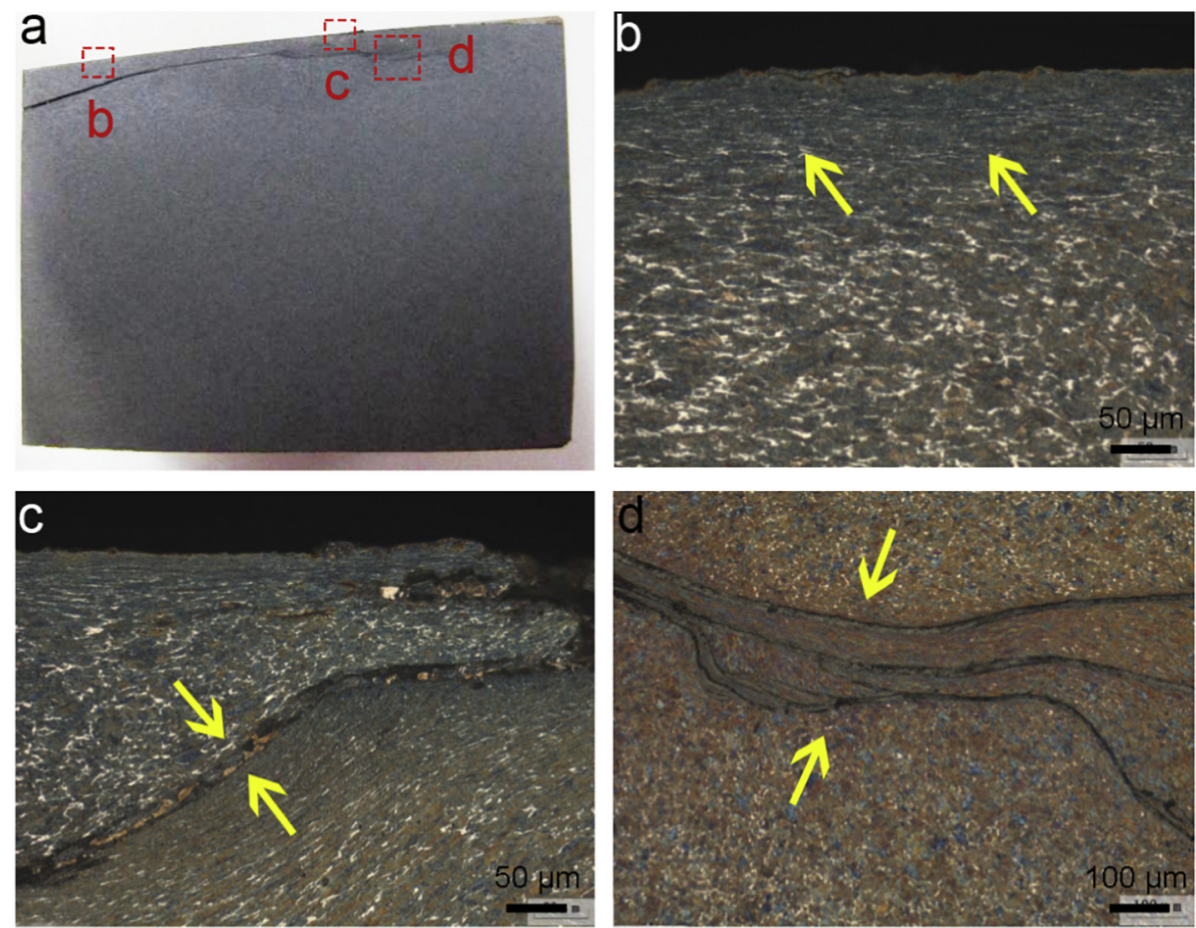

Fig. 13. Observations of the cracks and microstructure, (a) metallographic surface, (b) microstructure on the tread, (c) and (d) microstructure around the cracks.

presents the hardness distribution of the wheel profile. Fig. 16a shows the measure points and corresponding values of Brinell hardness. Vickers hardness was used in the prediction of fatigue strength in Eq. (1). Then, Fig. 16b presents the corresponding Vickers hardness distribution, indicating that the hardness value decreases gradually with an increasing depth from the tread. The hardness for the depth of $0-10 \mathrm{~mm}$ to the tread is in range of $270-280 \mathrm{Hv}$, The value of the hardness for the $10-25 \mathrm{~mm}$ depth is $260-270 \mathrm{Hv}$. Although the stress is larger in the surface, the gradient distribution of hardness for hard surface and soft core can suppress the surface crack initiation.

Fig. 17 presents the schematic for the formation mechanism of shattered rim and shelling induced by defects. When the defect locates at the subsurface of the tread with the depth $<10 \mathrm{~mm}$, crack induced by the defect will prefer to propagate to the tread instead of the rim, called shelling. This will cause damage on the tread, and influence the service of the wheel. With turning repair, the wheel can continue the service. When the defect is located at interior of the wheel and is deeper than $10 \mathrm{~mm}$, the crack will propagate to the rim instead of the tread. The shattered rim will lead to the failure of the wheel, even disaster to the train. Models such as "hydrogen assisted crack growth" [27,28], "decohesion of spherical carbide" [29,30], and "formation and debonding of fine granular layer" [19,20] have been proposed for describing the crack initiation mechanism for the VHCF of steels. For the mechanism of "hydrogen assisted crack growth", it was stated that the existence of locally concentrated hydrogen trapped by a defect induced the discrete crack growth at a very slow rate during crack initiation. The mechanism of "decohesion of spherical carbide" attributes the decohesions of spherical carbides from the matrix to the crack initiation of VHCF. The debondings of the fine granular layer and the matrix are responsible for the early cracks in the model of "formation and debonding of fine granular layer".

\section{Conclusions}

This paper investigates a VHCF behavior under rolling contact loading in railway wheels, i.e., the shattered rim and shelling. The VHCF under rolling contact loading has been rarely reported. The investigation of the shattered rim and shelling would enrich the topic of VHCF, meanwhile the existed VHCF theories can also guide the fatigue design of the railway wheels. The following conclusions are drawn.

- The recorded data of the last ten years CRH operation indicated that all shattered rims and shelling were detected with serving $>10^{6} \mathrm{~km}$ (corresponding to the fatigue life $10^{7}-10^{9}$ cycles) which is very-high-cycle fatigue (VHCF). Shattered rim initiation region located at the depth of $10-25 \mathrm{~mm}$ from the tread, while the shelling crack initiation region located at the depth $<10 \mathrm{~mm}$ from the tread.

- The VHCF features under rolling contact loading show the defect, fish-eye, and crack propagation region which is similar with the VHCF in uniaxial loading. Also novel VHCF features were also observed, i.e., the three dimensional crack surface features, beach 
a
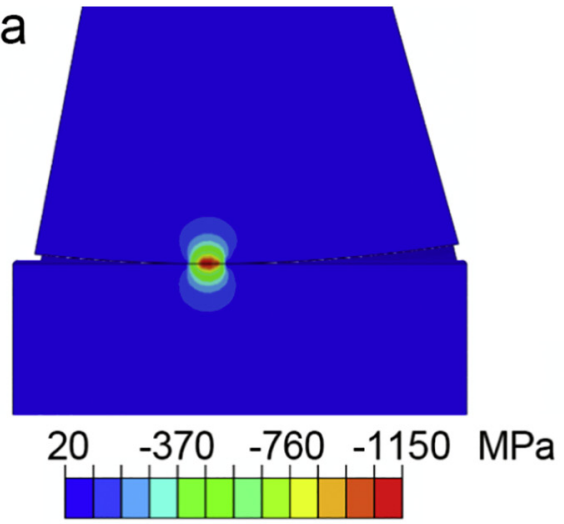

C
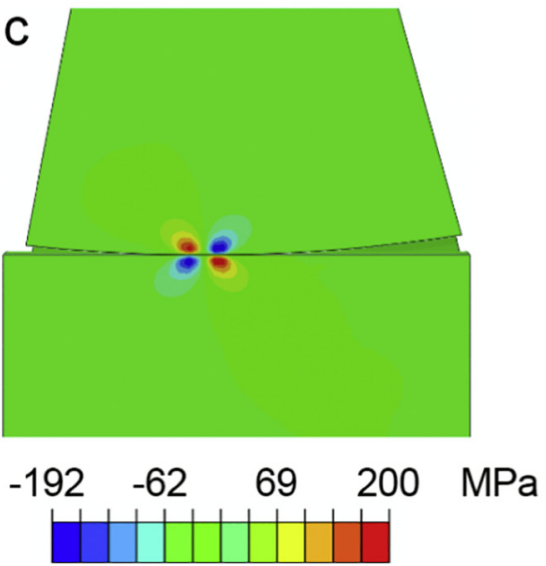

b

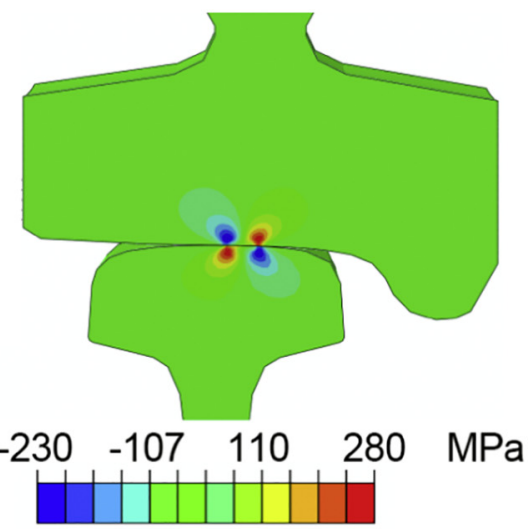

d

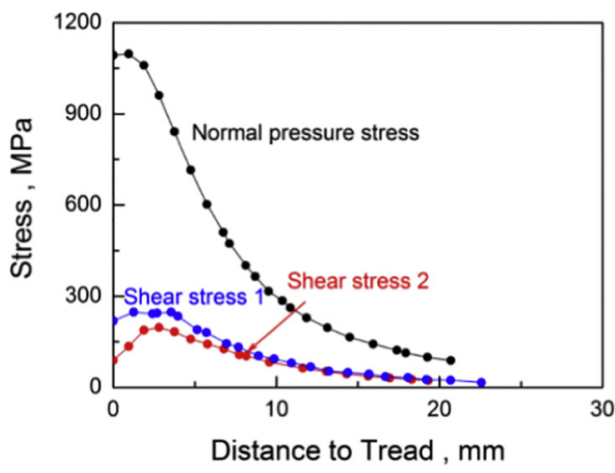

Fig. 14. Stress distribution of wheel/rail contact, (a) pressure stress contour in radial direction, (b) shear stress contour in axle direction, and (c) shear stress in circumference direction, and (d) stress variation along the radial direction of the wheel.

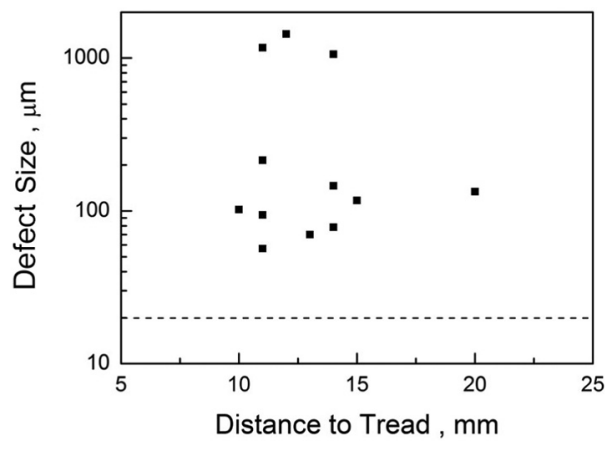

Fig. 15. Defect size versus depth from the tread.

bands uniformly distributed in the crack propagation region, and the absence of FGA.

- The multi-axial stress distribution, the large defect, the hardness distribution of hard surface and soft core are attributed to the formation of the shattered rim and shelling in VHCF regime.

\section{Acknowledgements}

The financial supports of the National Natural Science Foundation of China No. 11802011, the Joint Funds of the National Natural Science Foundation of China No. U1834202, the National Key Research and Development Program of China No. 2017YFB0702004, the 973 Programs under grant No. 2015CB654805, the Fundamental Research Funds for the Central Universities No. 2017RC028, and the National Key Technology R\&D Program under grant No.2015BAG12B01-09 are acknowledged. 


\section{a}

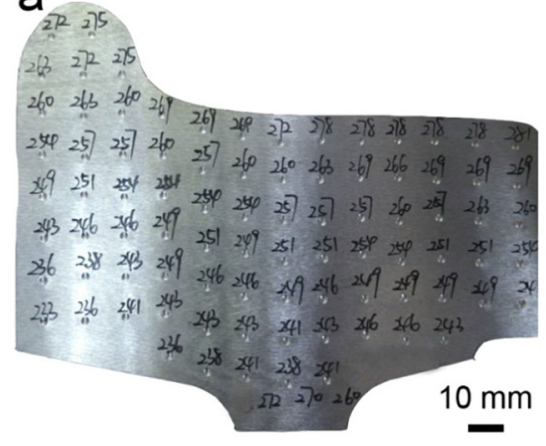

b

b

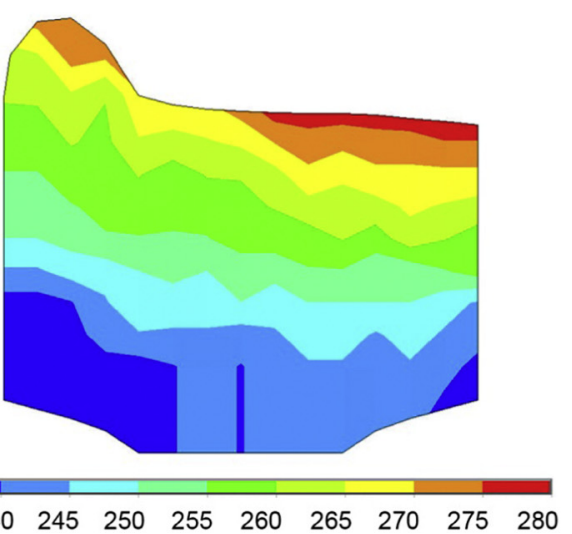

Fig. 16. Hardness distribution of the wheel profile, (a) measure points and corresponding values, and (b) corresponding Vickers hardness contour.

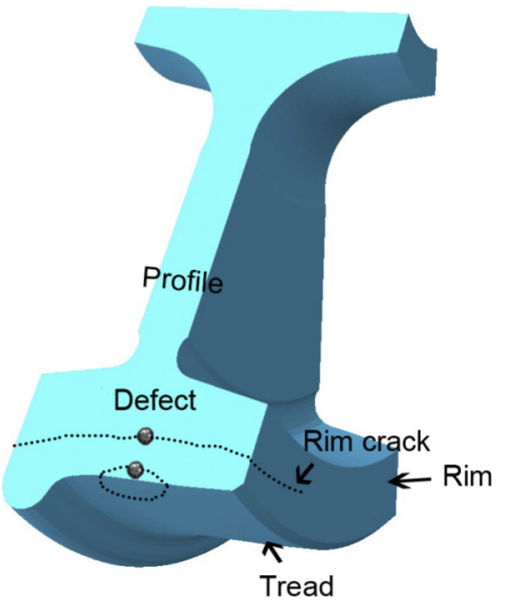

Fig. 17. Schematic of shattered rim and shelling induced by defects.

\section{References}

[1] J. Campos, G. De Rus, Some stylized facts about high-speed rail: a review of HSR experiences around the world, Transp. Policy 16 (1) (2009) 19-28.

[2] M. Givoni, Development and impact of the modern high-speed train: a review, Transp. Rev. 26 (5) (2006) 593-611.

[3] Y. Liu, L. Liu, S. Mahadevan, Analysis of subsurface crack propagation under rolling contact loading in railroad wheels using FEM, Eng. Fract. Mech. 74 (17) (2007) 2659-2674.

[4] P.J. Mutton, C.J. Epp, J. Dudek, Rolling contact fatigue in railway wheels under high axle loads, Wear 144 (1) (1991) $139-152$.

[5] G.N. Haidemenopoulos, P.I. Sarafoglou, P. Christopoulos, A.D. Zervaki, Rolling contact fatigue cracking in rails subjected to in-service loading, Fatigue Fract. Eng. Mater. Struct. 39 (2016) 1161-1172.

[6] A. Ekberg, B. Akesson, E. Kabo, Wheel/rail rolling contact fatigue - Probe, predict, prevent, Wear 314 (2014) 2-12.

[7] A. Ekberg, E. Kabo, Fatigue of railway wheels and rails under rolling contact and thermal loading-an overview, Wear 258 (2005) 1288-1300.

[8] A. Ekberg, E. Kabo, H. Andersson, An engineering model for prediction of rolling contact fatigue of railway wheels, Fatigue Fract. Eng. Mater. Struct. 25 (2010) 899-909.

[9] S.L. Dedmon, The process of spalling in railroad wheels, ASME 2011 Rail Transportation Division Fall Technical Conference, 54 (600) 2011 , pp. 167-172.

[10] T. Makino, M. Yamamoto, T. Fujimura, Effect of material on spalling properties of railroad wheels, Wear 253 (1-2) (2002) 284-290.

[11] A. Ekberg, E. Kabo, J.C.O. Nielsen, R. Lundén, Subsurface initiated rolling contact fatigue of railway wheels as generated by rail corrugation, Int. J. Solids Struct. 44 (2007) 7975-7987.

[12] D.F.C. Peixoto, P.M.S.T. de Castro, Fatigue crack growth of a railway wheel, Eng. Fail. Anal. 82 (2017) $420-434$.

[13] B. Alfredsson, J. Dahlberg, M. Olsson, The role of a single surface asperity in rolling contact fatigue, Wear 264 (2008) 757-762.

[14] X. Zhao, B. Xin, X. An, Z. Zhao, X. Jin Wen, Local rolling contact fatigue and indentations on high-speed railway wheels: Observations and numerical simulations, Int. J. Fatigue 103 (2017) 5-16.

[15] J. Sandström, Subsurface rolling contact fatigue damage of railway wheels - a probabilistic analysis, Int. J. Fatigue 37 (2012) $146-152$.

[16] Guian Qian, W.S. Lei, L. Peng, Z. Yu, M, Niffengger. Statistical assessment of notch toughness against cleavage fracture of ferritic steels, Fatigue Fract. Eng. Mater. Struct. 41 (2018) 1120-1131.

[17] Xiaolong Liu, Chengqi Sun, Youshi Hong, Effects of stress ratio on high-cycle and very-high-cycle fatigue behavior of a Ti-6Al-4V alloy, Mater. Sci. Eng. A 622 (2015) 228-235.

[18] Xiaolong Liu, Chengqi Sun, Youshi Hong, Faceted crack initiation characteristics for high-cycle and very-high-cycle fatigue of a titanium alloy under different stress ratios, Int. J. Fatigue 92 (2016) 434-441.

[19] T. Sakai, N. Oguma, A. Morikawa, Microscopic and nanoscopic observations of metallurgical structures around inclusions at interior crack initiation site for a bearing steel in very high-cycle fatigue, Fatigue Fract. Eng. Mater. Struct. 38 (2015) 1305-1314. 
[20] T. Sakai, Y. Sato, N. Oguma, Characteristic S-N properties of high-carbon-chromium-bearing steel under axial loading in long-life fatigue, Fatigue Fract. Eng. Mater. Struct. 25 (2002) 765-773.

[21] A. Grabulov, R. Petrov, H.W. Zandbergen, EBSD investigation of the crack initiation and TEM/FIB analyses of the microstructural changes around the cracks formed under Rolling Contact Fatigue (RCF), Int. J. Fatigue 32 (2010) 576-583.

[22] A. Grabulov, U. Ziese, H.W. Zandbergen, TEM/SEM investigation of microstructural changes within the white etching area under rolling contact fatigue and 3-D crack reconstruction by focused ion beam, Scripta Mater. 57 (2007) 635-638.

[23] A.G. Zhao, J.J. Xie, C.Q. Sun, Z.Q. Lei, Y.S. Hong, Effects of strength level and loading frequency on very-high-cycle fatigue behavior for a bearing steel, Int. J. Fatigue 38 (2012) 46-56.

[24] T. Sakai, B. Lian, M. Takeda, K. Shiozawa, N. Oguma, Y. Ochi, et al., Statistical duplex S-N characteristics of high carbon chromium bearing steel in rotating bending in very high cycle regime, Int. J. Fatigue 32 (2010) 497-504.

[25] Y. Murakami, T. Nomoto, T. Ueda, Factors influencing the mechanism of superlong fatigue failure in steels, Fatigue Fract. Eng. Mater. Struct. 22 (7) (1999) $581-590$.

[26] Y. Murakami, N.N. Yokoyama, J. Nagata, Mechanism of fatigue failure in ultralong life regime, Fatigue Fract. Eng. Mater. Struct. 25 (8-9) (2002) 735-746.

[27] Y. Murakami, T. Nomoto, T. Ueda, Y. Murakami, On the mechanism of fatigue failure in the superlong life regime (N $>10^{7}$ cycles). Part I: influence of hydrogen trapped by inclusions, Fatigue Fract. Eng. Mater. Struct. 23 (2000) 893-902.

[28] Y. Murakami, T. Nomoto, T. Ueda, Y. Murakami, On the mechanism of fatigue failure in the superlong life regime (N $>10^{7}$ cycles). Part II: a fractographic investigation, Fatigue Fract. Eng. Mater. Struct. 23 (2000) 903-910.

[29] K. Shiozawa, L. Lu, S. Ishihara, S-N curve characteristics and subsurface crack initiation behaviour in ultra-long life fatigue of a high carbon-chromium bearing steel, Fatigue Fract. Eng. Mater. Struct. 24 (2001) 781-790.

[30] K. Shiozawa, Y. Morii, S. Nishino, L. Lu, Subsurface crack initiation and propagation mechanism in high-strength steel in a very high cycle fatigue regime, Int. J. Fatigue 28 (2006) 1521-1532. 